\title{
Áreas de servicio, producción y almacenaje en los espacios domésticos romanos del territorio valenciano
}

\author{
Areas of service, production and storage in the Roman \\ domestic spaces of the Valencian territory
}

\author{
Tamara Peñalver Carrascosa \\ Universidad de Valencia. Departamento de Prehistoria, Arqueología e Historia Antigua \\ Avda. Blasco Ibáñez, 28, E-46010 València \\ tamara.penalver@uv.es
}

Este artículo tiene como objetivo visibilizar las áreas de servicio, producción y almacenaje de los ambientes domésticos romanos encontrados en el territorio valenciano. Estos espacios, tradicionalmente marginados por la historiografía, fueron de vital importancia en el funcionamiento de la casa, desde aspectos como la subsistencia básica hasta actividades de representación ligadas al acto del banquete. Se realiza una propuesta metodológica de identificación de estos espacios a través de estructuras fijas funcionales, técnicas y materiales constructivos, y presencia de cultura material mueble.

PALABRAS CLAVE

ARQUITECTURA DOMÉSTICA, DOMUS, ESPACIOS SERVILES, CULINAE, ESPACIOS PRODUCTIVOS

The aim of this article is to make visible the service, production and storage areas of the Roman domestic spaces found in the Valencian territory. These environments, traditionally marginalized by historiography, were essential in the running of the household, from activities of basic subsistence to the rituals of representation linked to the act of the banquet. We will present a methodological proposal to identify large service areas, kitchen and production spaces through fixed functional structures, techniques and construction materials.

\section{KEYWORDS}

DOMESTIC ARCHITECTURE, DOMUS, SERVICE AREAS, CULINAE, PRODUCTION SPACES 


\section{Introducción}

El estudio de los ambientes de servicio se ha caracterizado tradicionalmente por el escaso interés recibido por parte de la bibliografía. Sin embargo, recientes estudios sobre la casa prestan más atención a los aspectos humildes de la vida cotidiana, tratando de observar el funcionamiento de la vivienda. No solo desde el punto de vista del propietario, sino de todos aquellos siervos que, no habiendo dejado claras señales en el registro arqueológico, serían omnipresentes en la escena doméstica. ${ }^{1}$

Se podría pensar que estos ambientes son fácilmente reconocibles dentro de la casa, ya que tienen que cumplir con unas funciones específicas (Bonini y Dal Porto, 2003: 467468). Sin embargo, los espacios de servicio se caracterizan por su pluralidad de formas, lo que transmite la impresión de que no se pensaban en su fase constructiva, sino que se organizaban en un segundo momento o que se ubicaban en habitaciones dedicadas primero a otros usos (Bonini, 2015: 459). Entre ellos se encuentran las cocinas, las letrinas, los almacenes de todo tipo, los espacios productivos, etc.

Definidos como espacios estáticos con función específica por Foss, los espacios de servicio son ambientes flexibles que suelen aparecer planimétricamente subordinados a los ambientes de representación (Foss, 1994: 38). Estas áreas son más fáciles de detectar en casas grandes, que dedicarían diversos espacios a este fin, mientras que en casas pequeñas el número de estancias de servicio, así como el de esclavos, sería menor o incluso inexistente. En muchos casos estos espacios podrían estar en pisos superiores no preservados (George, 1997a: 20-21).

Nuestro objetivo en este artículo es recopilar diversos ambientes de servicio encontrados en las domus valencianas (fig. 1), con el fin de extraer conclusiones respecto a su morfología, ubicación en planta e interacción con otros ambientes de la casa. Condicionado por las evidencias arqueológicas conservadas, el estudio abordará el reconocimiento de áreas de servicio que pertenecieron mayoritariamente a domus acomodadas.

\section{Propuesta metodológica para la identificación de estos espacios}

La línea metodológica escogida para su identificación, tal y como hacen Bonini y Rinaldi (2003: 190), pasa por el reconocimiento, no de aquello que pertenece a la esfera del servus, sino de aquello que pertenece a la vida del dominus. Es decir, el marcador de un espacio servil es precisamente la ausencia de las características lujosas que encontramos en el área

1. Salza, 1978-1980: 237-294; Riva 1999: 117-128; Bonini, 2015: 455-474; Kastenmeier, 2007; Bonini y Dal Porto, 2003: 465-492; Basso, 2003: 519-566; Bonini y Rinaldi, 2003: 189-220; Foss, 1994; Jansen, 1997: 121-134; George, 1997a: 299-320; 1997b: 299-320. 
Figura 1. Ciudades romanas en territorio valenciano.

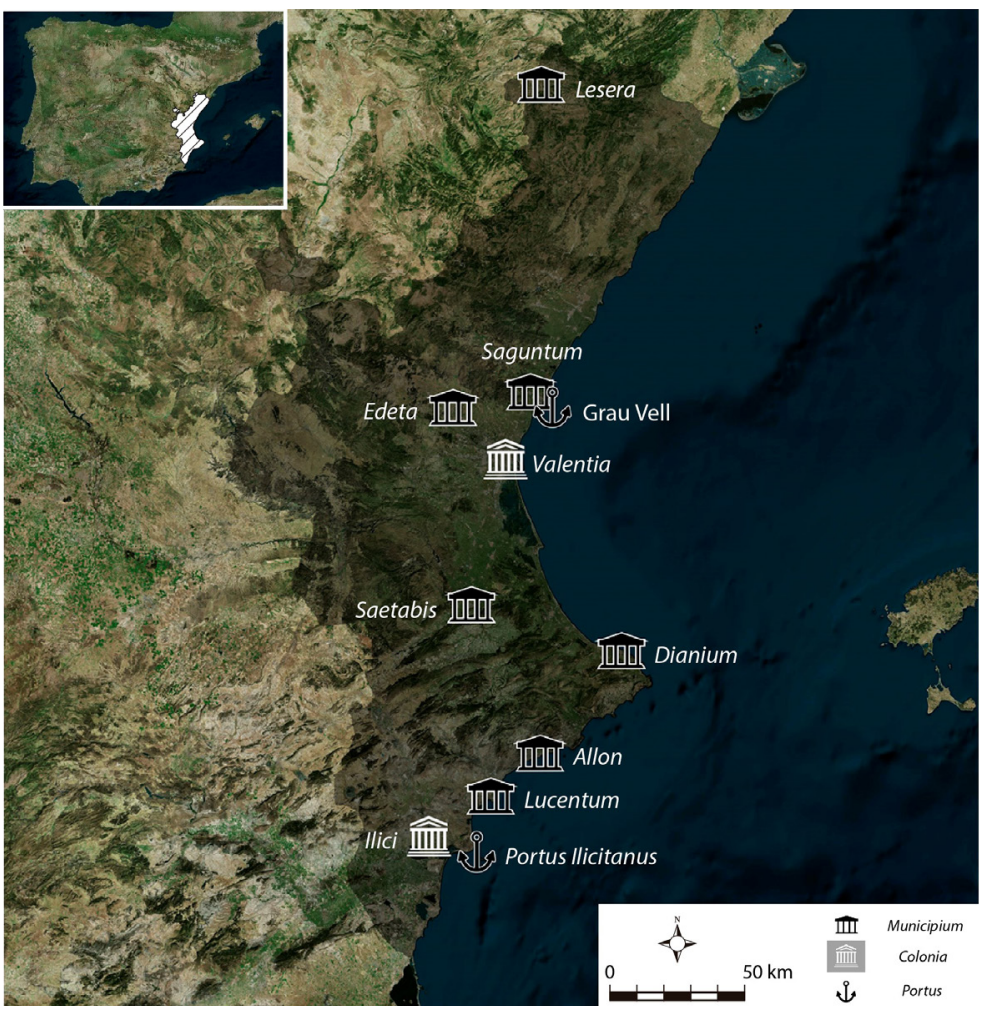

noble. Sin embargo, hay que tener en cuenta que, como indicaba Zanker, los confines entre ambos ámbitos no eran rígidos (Zanker, 1993: 16; Bonini y Rinaldi, 2003: 190).

Entre los ambientes considerados de servicio destacan, por su mayor atención historiográfica, las cocinas, entendidas como ambientes de reducidas dimensiones que no suelen superar los 10-15 m² (Kastenmeier, 2007: 58-60). Entre los elementos escogidos para su identificación destacan, por su claridad, las estructuras fijas funcionales, como los bancos de cocción; sin embargo, su práctica total ausencia fuera del territorio campano, ${ }^{2}$ con alguna excepción en Ostia Antica, nos hace centrar la atención en soluciones alternativas para las cocinas provinciales, como los hogares que aparecen directamente sobre los pavimentos o los elementos muebles, como opción más económica, que de igual modo permitirían cocinar. Los pequeños hornos transportables podían sustituir al banco o completarlo; de diversas formas y materiales, rectangulares o redondos, con espacios delanteros para apoyar la vajilla sobre las brasas, con los bordes realzados... hay braseros que solo sirven para mantener el

2. Tampoco se encuentran en el África Proconsular, con un solo ejemplo aislado en la Nympharum Domus en la Neapolis (Nabeul, Túnez) (Bonini y Rinaldi, 2003: 192). 
calor y otros, con una boca de alimentación para las brasas en la parte inferior y abiertos en la parte superior, para cocinar (Bonini y Dal Porto, 2003: 469; Kastenmeier, 2007: 69-85). Pueden ser de cerámica o de metal (bronce o hierro), lo que explicaría su ausencia en muchos de los casos, ya que una vez inservibles se fundirían (Salza, 1978-1980: 280-282).

Sin embargo, tal afirmación no está exenta de polémica, ya que en el estudio realizado por Riva para las cocinas de Ostia Antica, se plantea la ausencia de bancos de mampostería a causa de su destrucción, al no haber sobrevivido a la historia de la ciudad y de sus excavaciones (Riva, 1999: 118-125). No obstante, y en nuestra opinión, consideramos que la falta de evidencia se convierte en una evidencia en sí misma; no creemos probable que todos los bancos de mampostería fuera de la zona campana hayan sido destruidos. No descartamos la existencia de casos aislados que hayan sido arrasados, pero en el caso valenciano es evidente que tuvieron que existir alternativas para cocinar, como hogares, cocinas y braseros portátiles.

Por tanto, a pesar de que resulta complicado poder identificar estos espacios por la ausencia de elementos estructurales, sea porque nunca fueron construidos o porque se perdieron, esto no significa que las cocinas no existieran, sino que la modalidad de cocción de los alimentos fue diversa. Por tanto, la identificación de estos espacios deberá basarse en el reconocimiento de una serie de elementos que puedan constituir indicadores fiables (Bonini y Dal Porto, 2003: 470; Bonini y Rinaldi, 2003: 197).

En lo constructivo, los pavimentos y paredes de estas estancias, se caracterizan por ser de fácil limpieza y mantenimiento. Los pavimentos suelen ser de tierra batida, piedra volcánica, losas de ladrillo y tejas; es decir, materiales simples, económicos, duros y resistentes al agua (Joyce, 1979: 256). Las paredes, generalmente enyesadas, podían tener zócalos de color rojizo, ricos en polvo de ladrillo y más resistentes al agua; además, la ausencia de recubrimientos pictóricos se debería a que los propietarios no creían necesario decorarlas, dados los usuarios de estos espacios, esclavos o libertos (Kastenmeier, 2007: 23-27).

En cuanto a la planimetría, la relación con otras estancias de servicio - almacenes o estancias que necesitaran de las mismas instalaciones para funcionar-, como letrinas o termas, es otro indicativo que nos puede ayudar a identificar estos espacios. Las letrinas pueden tener un ambiente propio o situarse junto al banco de la cocina. Destaca también su unión con las termas, en aquellas casas que las poseyeran, ya que ambas hacen uso de agua y fuego (Salza, 1978-1980: 243-256; Jansen, 1997: 128-129).

En período imperial encontramos fuentes que nos cuentan que se cocinaba en las salas de banquetes. Séneca (Sen., Ep., 78. 23) dice que «[...] es el procedimiento que ha ideado ahora nuestro sibaritismo: para evitar que algún plato se enfríe, que algún bocado resulte poco caliente al paladar ya endurecido, se traslada a la mesa la cocina [...]» refiriéndose a braseros portátiles, normalmente llamados foculi o foculares. Todas estas opciones demuestran que la cocina no se entiende como un área fija, sino como el lugar donde se llevan a cabo actividades culinarias (Foss, 1994: 70-73).

Por otra parte, a pesar de que su situación en planta sigue criterios pragmáticos y suele aparecer subordinada a las áreas residenciales, hay una voluntad de excluir visual 
y estructuralmente estos espacios de los ambientes de habitación. Wallace-Hadrill (1988: 81) reconoce cómo las áreas de bajo estatus debían ser invisibles para el visitante. Se suele seleccionar un espacio periférico, junto a muros perimetrales, para responder a exigencias prácticas como la salida de humos, la evacuación de aguas y el control de posibles incendios y, por otra parte, intentar que el servicio sea lo más rápido posible (Riva, 1999: 117), por lo que la posición ideal de una cocina era próxima a un ingreso, lateral o posterior (posticum) y en torno a un largo pasillo o a patio de servicio, generalmente descubierto (Kastenmeier, 2007: 85-88; Salza, 1978-1980: 267-268).

Relacionados con la ubicación aparecen dos factores fundamentales: los sistemas de aireación y de iluminación. Si no se podían ubicar ventanas a la calle porque se encontraban en lugares interiores o patios internos, se podía abrir un agujero en el techo (Kastenmeier, 2007: 58-60). En ocasiones, la indiferencia respecto a la salida de humos y el óptimo estado de conservación de los revestimientos parietales, sin ennegrecer, nos hace pensar que se cocinaba sobre brasas (Bonini, 2015: 459).

Aunque el agua era imprescindible en el desarrollo de las labores de la casa, solo en pocas ocasiones se llevaba directamente a cocinas, baños o letrinas (Jansen, 1997: 130131; Kastenmeier, 2007: 19-20), por lo que su localización no es un elemento útil en la identificación.

Por último, ante la ausencia generalizada de elementos estructurales en las domus provinciales, consideramos que la clave para su localización reside en la cultura material mueble, recipientes de cocina, almacenaje, vajilla, que se podían colgar de las paredes, disponerse en estanterías o sobre el suelo (Kastenmeier, 2007: 66-67).

Nos gustaría matizar que nuestra intención no es realizar un estudio aislado de las diversas estancias, sino observar cómo se articulan entre sí, para poder comprender la vida en la casa y sus flujos (Bonini y Rinaldi, 2003: 191); sin embargo, esta interrelación solo es observable en planimetrías completas, que solo conservamos en un bajo porcentaje de casos. En este sentido, Foss (1994) definió una serie de factores para analizar la relación entre espacios de servicio y de representación:

- La proximidad entre ambos espacios, en relación con la energía y tiempo requeridos para moverse a través del camino más corto.

- La accesibilidad, dependiendo de los espacios que se tienen que atravesar entre la cocina y la sala de banquetes.

- La percepción, a través de la vista, el oído y el olfato.

- Las instalaciones, disponibilidad de agua, desagües, fuegos, luz, ventilación, proximidad de letrinas y baños (Foss, 1994: 38-42).

- La ritualidad vinculada con el fuego presente en estos espacios.

En conclusión, aunque es cierto que hay una aspiración a segregar la cocina de los espacios serviles, la exigencia de garantizar un servicio rápido durante los banquetes hace que no se aleje mucho de los triclinia (Bonini, 2015: 468). 
También estos ambientes reflejan diferencias sociales, pues dependiendo de la disponibilidad de espacio de una casa podemos encontrar todo un sector servil, mientras que en las casas más pobres basta con un pequeño banco en una esquina de un patio, si es que lo hay (Salza, 1978-1980: 266-267).

Por tanto, los factores que tendremos en cuenta para la identificación de estos espacios serán: los mobiliarios fijos funcionales (hogares, hornos, bancos de cocina), la cultura material mueble, las paredes y los suelos con materiales resistentes y de fácil limpieza, y su ubicación en sectores cercanos al perímetro de la casa, próximos a una entrada secundaria.

En este artículo presentamos las evidencias divididas en áreas de servicio que engloban cocinas, almacenes y letrinas, y espacios de producción, identificados por prensas de aceite, vino, hornos de vidrio, metal, etc.

\section{Ambientes de servicio}

En primer lugar, analizaremos las viviendas que han realizado una inversión espacial en ejes de servicio tan considerable que se convierte en un indicativo del estatus social de sus propietarios (Kastenmeier, 2007: 28-27). El segundo subapartado recogerá las estancias identificadas por estructuras fijas funcionales, como hornos y hogares. Y el tercer grupo reunirá los espacios identificados por la presencia de cerámica de cocina, almacenaje o vajilla.

\subsection{Ejes de servicio}

\subsubsection{Domus tardía del solar del Romeu (Saguntum)}

Las diversas estancias encontradas en esta domus, datadas entre los siglos III-IV dC, parecen corresponderse con un gran eje de servicio (fig. 2). A pesar de su planimetría incompleta y del arrasamiento posterior, producido por la superposición de estructuras medievales, podemos delimitar una serie de habitaciones cuya funcionalidad puede inferirse a través del estudio de las estructuras, los materiales y las técnicas constructivas.

En el muro perimetral $\mathrm{N}$ se abren dos estancias (6 y 7), que podrían identificarse como espacios comerciales o tabernae. Junto a ellas se conserva un acceso (Chiner y López, 1994: 232), abierto a una estancia rectangular (1), solada con dos pavimentos superpuestos. Este acceso podría ser una entrada de servicio, ya que las zonas serviles/productivas podían contar con patios secundarios con accesos propios, para no interferir en espacios destinados a la familia (Ghedini, 2003: 117). Además, la ubicación de esta estancia, junto a una calle de 2,90 m de anchura, que permitiría el paso de carros de acuerdo con la medida estándar de 1,40 m, extraída de las carriladas de Pompeya, podría estar indicando un posible acceso de carros. 
Figura 2. Domus tardía del solar del Romeu (Saguntum) (a partir de Chiner y López, 1994: 231, fig.1).

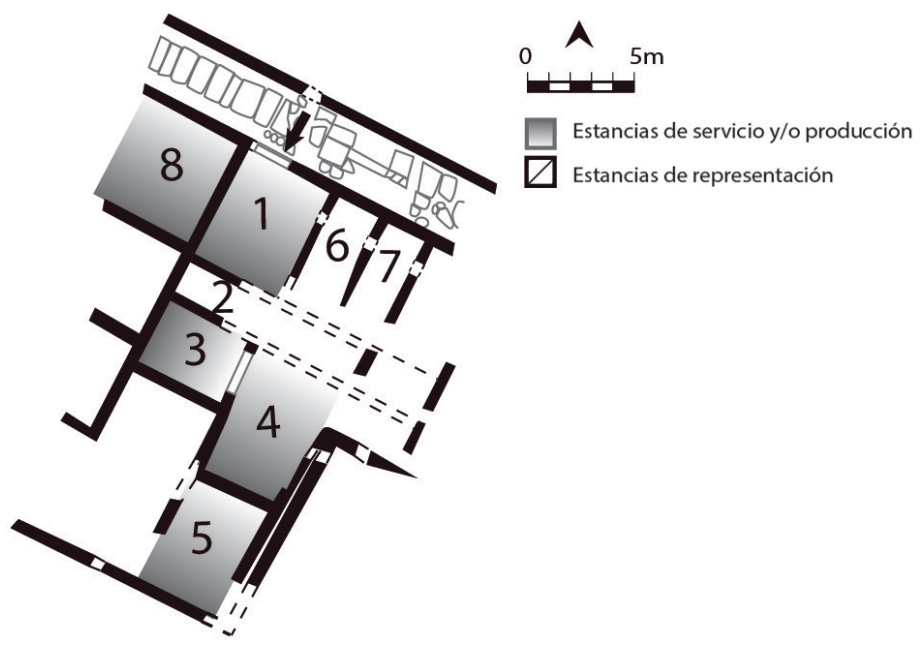

Por otra parte, para permitir el paso de carros, el umbral debía tener, como mínimo, 1,50 m y estar conectado con un ambiente o patio amplio; ambas condiciones se cumplen en la domus saguntina. El estudio de Kastenmeier certifica que tener animales en el interior de las casas era una práctica muy difundida. Estos espacios solían situarse separados de otros ambientes de servicio como la cocina, la letrina, los almacenes... (Bonini, 2006: 103; Kastenmeier, 2007: 38-41), razón por la que dichos espacios aparecen separados de un segundo patio de servicio.

La memoria de excavación menciona la aparición de fragmentos de enlucido rojo entre el derrumbe (Chiner y López, 1994: 232-233), que podrían relacionarse con el color propio del óxido de hierro, con numerosos paralelos pompeyanos, más resistentes al agua, aumentando su practicidad (Kastenmeier, 2007: 23-24).

El ambiente 3 está pavimentado con losas de rodeno colocadas sobre las zapatas de los muros E y $\mathrm{S}$ de la estancia, cubriendo lo que parece un canal hidráulico, sin que conozcamos en qué dirección desaguaba. Esta estancia comunica con un patio empedrado (4) situado al E, a través de un umbral de caliza con la huella del gozne. En los restos musealizados se observa el arranque de un muro, al $\mathrm{N}$ del patio (4), sobre el que descansa una basa de columna que podría formar parte de un porticado, amortizado posteriormente.

El pavimento se realizó a base de cantos rodados apisonados y trabados con mortero, sobre él aparecieron abundantes fragmentos de dolia, lo que reafirma el carácter servil de este espacio, caracterizado por los recipientes de almacenaje.

La habitación 5, enmarcada por dos muros de técnica muy cuidada, al N y al E, está pavimentada con tejas y losas de caliza y rodeno, lo que facilitaría las tareas de limpieza. Los responsables de la excavación describen lo que parece ser un horno excavado bajo el nivel del suelo sobre gravas estériles; sobre él se encontró una capa de cenizas, con abundante cerámica de cocina común y lucernas. Por tanto, los materiales aparecidos junto a 
esta estructura llevaron a identificarla como posible cocina (Chiner y López, 1994: 233). No obstante, no conocemos su conexión con el resto de estancias, ya que no presenta vano alguno que la conectara con el patio empedrado. Por otra parte, el arrasamiento de las estructuras al $\mathrm{O}$ de la estancia 5 nos impide detectar su conexión con el resto de la casa.

La habitación 8 no tiene una relación espacial con el resto de estructuras, aunque no descartamos que el pasillo (2) presentara un acceso a ella. En esta estancia, bajo ánforas africanas de época bajoimperial, se encontraron 11 sestercios que parecían haber estado en un estuche-saco de material orgánico desaparecido, así como un zarcillo de oro y varios objetos de adorno, además de un depósito monetal, donde aparecieron seis monedas dispersas. La ocultación sería poco después de la acuñación del sestercio de Balbino (238 dC). Aunque el hallazgo de objetos suntuarios y la aparición de pinturas murales en una habitación contigua llevaron a los investigadores a identificarla como una estancia noble de la casa (Chiner y López, 1994: 235; Llorens y Ripollés, 1995: 217-228), la presencia de ánforas en su interior nos lleva a identificarla, al menos durante su última fase, como estancia de almacenaje. A pesar de la complicada lectura mural derivada de la superposición de estructuras medievales, podemos afirmar que se trata de la parte servil de la casa. El horno encontrado en la estancia 5, el tipo de pavimentos funcionales, la ausencia de enlucidos y los restos de cerámica de cocina y almacenaje encontrados corroboran la hipótesis. Por otra parte, dada la afortunada presencia de las calles, parece que el acceso principal de esta domus estaría situado en la calle que atraviesa el solar de N-S y que constituye el eje de mayor importancia de este sector urbano, mientras la calle E-O, de carácter secundario, se pondría en relación con un segundo acceso que facilitaría la llegada de provisiones, como sucede en la Casa deii Vettii (VI, 15, 1) (Pompeya) (Kastenmeier, 2007: 28-27).

\subsubsection{Domus II (Edeta)}

A pesar de estar muy afectada por las obras de construcción de un muro de contención de época moderna, en la Domus II (Edeta) se han podido identificar dos áreas con funcionalidades diversas (fig. 3). Al SO se encuentra un conjunto de tres estancias con muros de mam-

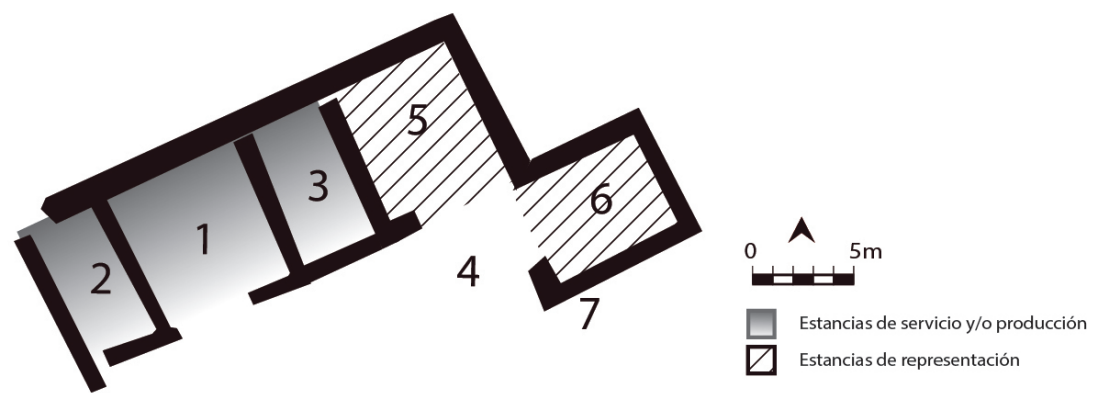

Figura 3. Domus II (Edeta) (a partir de Vidal, 2018: 14; fig. 5). 

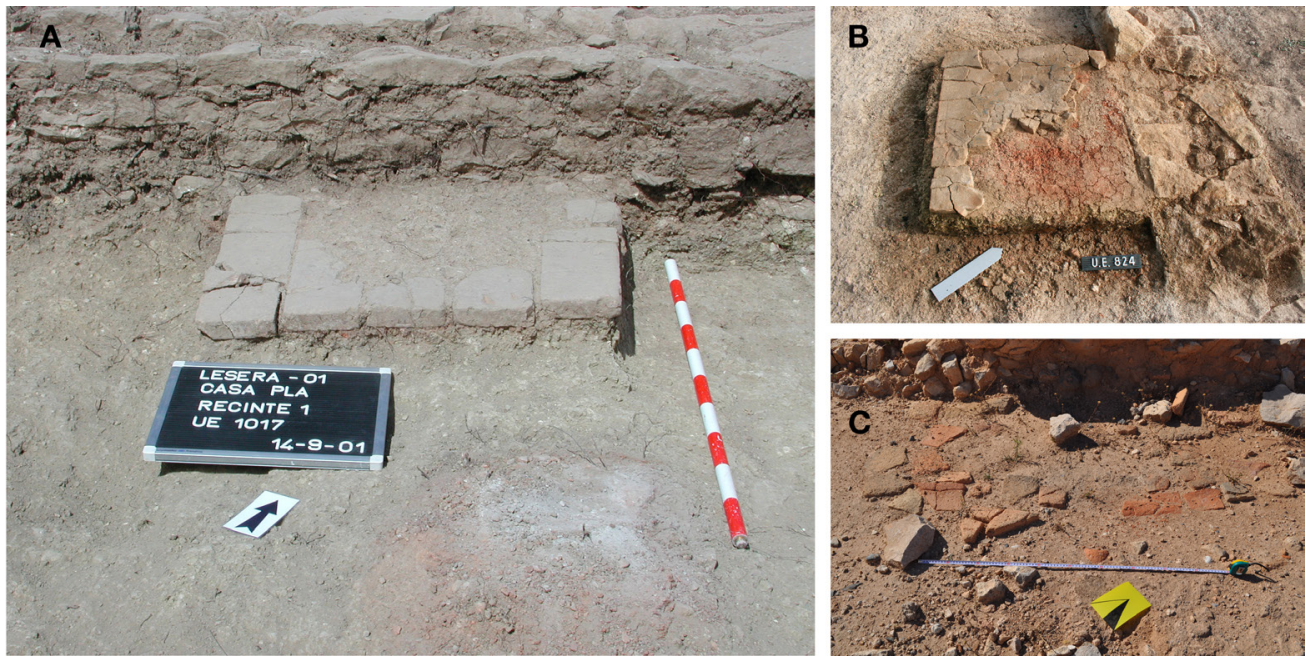

Figura 4. Hogares: A. Domus 1 (Lesera) (Arasa, 2009: 68; fig. 53); B. Sondeo 8 (Lesera) (fotografía cedida por F. Arasa); C. Domus II (Edeta) (fotografía de la autora).

postería, que podrían ser la parte de servicio de la casa. La estancia central (1) podría ser una cocina, por la presencia de un hogar sobre lateres quemados (fig. 4.c), con dos salas a ambos lados de morfología rectangular ( 2 y 3), bastante estrechas, que podrían ser espacios de almacenaje asociados a la cocina central, mientras al NE se desarrollaría la parte noble de la casa (5 y 6) (Vidal, 2018: 20-21). La asociación de tres estancias de servicio, bajo un esquema de amplia estancia central con hogar flanqueada por dos pequeñas habitaciones, es muy común en las viviendas de La Caridad (Caminreal, Teruel); señalamos como caso paradigmático la Casa de Likine. También aparecidos en Olynthus (Uribe, 2015: 153).

\subsubsection{Domus calle Sabaters-plaza de Cisneros (Valentia)}

En esta casa datada entre los siglos II-IV dC también se registró un eje de servicio (fig. 5). En la habitación 2 se ha recuperado gran cantidad de cerámica común africana, y destaca la presencia de un ánfora entera tipo Keay XIX. Sobre un hogar de tierra cocida y planta circular excavado en el suelo al S de la estancia, con manchas de carbones, apareció un caldero de bronce de dos asas. Este indicio estructural de un hogar, junto con los materiales hallados, indica una funcionalidad de almacenaje y cocina. Su muro E se corresponde con el muro perimetral de la vivienda, en contacto con la calle, por lo que también aquí parece cumplirse la característica de una ubicación periférica que permitiría la ventilación de la estancia. A su vez, se encuentra abierta a lo que parece ser un espacio redistribuidor descubierto, pavimentado con cocciopesto (Albiach y Soriano, 1991a: 59, 1991b: 79). 


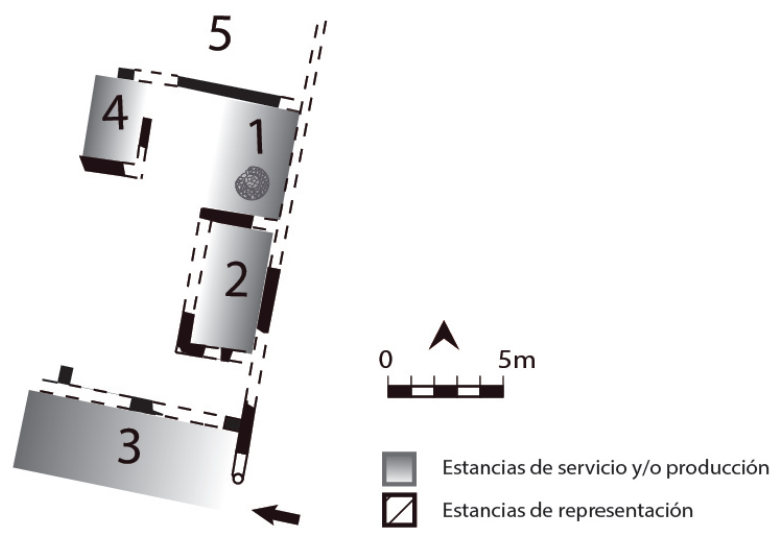

Figura 5. Domus de la calle Sabaters-plaza Cisneros (Valentia) (a partir de Albiach y Soriano, 1991a: 58; lámina 1).

La habitación 3, delimitada por dos paramentos, conserva un vano, abierto a la calle, con un fuste en uno de sus lados. En el centro de la estancia apareció un dolium, por lo que podríamos inferir una funcionalidad de almacenaje para este recinto (Albiach y Soriano, 1991a: 59); sin embargo, Serrano lo define como posible establo y sitúa los dolia en época altoimperial (Serrano, 2000: 14-15). Sus grandes dimensiones, aunque parcialmente conservadas, y su contacto directo con la calle hacen factible que desempeñara esta función.

Se han preservado restos de pintura mural en las estancias 2, 3 y 4 con colores rojos, blancos, amarillos, azules, verdes y negros, solos o combinados formando motivos geométricos y vegetales (Albiach y Soriano, 1991b: 77). Su decoración, muy fragmentada, representaba motivos vegetales: racimos de uva de color amarillento, con un fondo bicolor consistente en azul en la parte superior y blanco, en la inferior (Monraval, 1992: 57). Este tipo de decoración es inusual en las cocinas, por lo que podría tratarse de un caso de transformación del espacio o bien de una excepción, ya que en algunas cocinas pompeyanas han aparecido representados motivos vegetales y de uva (Foss, 1994: 43). Junto a estas estancias se encuentran otras dos ( 1 y 4), dedicadas a la producción de vidrio. Por tanto, se concluyó que se trataba de un espacio doméstico-artesanal, con estancias dedicadas a la elaboración de vidrio, almacenaje y cocina (Albiach y Soriano, 1991a: 60).

\subsubsection{Domus del Peristilo (Lucentum)}

Es una vivienda altoimperial (siglos I-II dC) de $400 \mathrm{~m}^{2}$, que se construye sobre el lienzo de la muralla púnica preexistente debido a la falta de espacio edificable (fig. 6). Adosados a la cara externa de la muralla, con más de $2 \mathrm{~m}$ de desnivel, se conservan cinco departamentos que servirían, desde el punto de vista estructural, como sostruzione cava para la parte noble. ${ }^{3}$

3. Realizamos un estudio más profundo sobre esta vivienda en Peñalver, 2018: 225-240. 

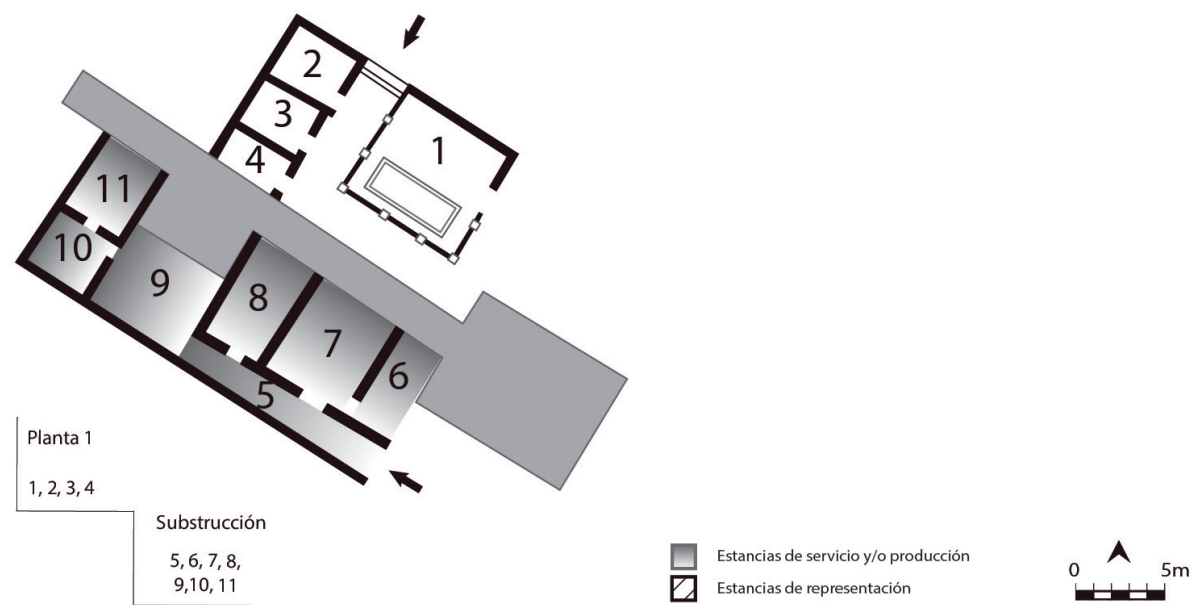

Figura 6. Domus del Peristilo (Lucentum) (a partir de Olcina, 2009: 106).

El acceso a ellos se realizaría a través de un corredor (5), aparentemente de servicio, que haría las veces de distribuidor dando paso a tres grandes estancias (6, 7 y 8 ) que podrían desempeñar la función de almacenes. Este pasillo termina en un espacio cuadrangular (9), que funcionaría también como distribuidor. A él se abre la estancia 10, conectada interiormente con la estancia 11, que no tiene vano abierto al espacio 9, por lo que se define como una estancia auxiliar de la anterior. Estas habitaciones pudieron constituir una posible cocina y/o almacén, conectadas entre sí, como podemos ver en la Casa Norte del yacimiento de Arucci (Huelva), donde la cella penaria tiene acceso al espacio distribuidor, y solo se puede acceder a la culina a través de ella (Corrales et al., 2016: 210). La planta en L de este conjunto de habitaciones presenta paralelos en el corredor 18 del edificio dei tre Bacini en Thuburbo Maius (Túnez), que recoge tres pequeños ambientes artesanales, o la Casa dell'Efebo en Volubilis (Marruecos) (Bonini y Rinaldi, 2003: 208).

Pensamos que, dada la cota de esta planta, pudiera tratarse de ambientes de servicio tales como almacenes y cocina, que servirían de base estructural para el piso superior situado a la cota del patio porticado, ubicado en el interior de la muralla. Es posible que ambos pisos estuvieran conectados a través de una escalera, cuya caja no se ha conservado. Somos conscientes de la prudencia que exigen los restos conservados, pero la ubicación de ambas plantas, la técnica constructiva, con los muros inferiores $10 \mathrm{~cm}$ más anchos que los superiores, así como la presencia de sillares esquineros, pudieran estar indicando que se trataría de paramentos que soportan las estructuras de una segunda planta.

Este sistema respondería al término constructivo de sostruzione cava, entendida por Zaccaria como un organismo articulado, con unas zonas llenas y otras vacías (Zaccaria, 2003: 67-69). Aunque las cocinas en substrucciones presentan algunos problemas respecto 
a los factores de proximidad y accesibilidad (Foss, 1994: 39), contribuían a separar olores y ruidos de la parte noble (Bonini, 2015: 461; Kastenmeier, 2007: 31-35).

Los paralelos más próximos, por la técnica constructiva y la ubicación de las domus, se encuentran en las casas aterrazadas de Pompeya y en Herculano, con estancias de servicio semienterradas, sobre todo en la Insula Occidentalis y la Insula VII, 2, que tenían asegurada la renovación de aire a través de las ventanas que se abrían hacia la costa (Bonini y Dal Porto, 2003: 478). Hay muchos ejemplos pompeyanos de estancias utilitarias en niveles subterráneos, como la Casa de Paquius Proculus (1, 7, 1), la Casa del Cinghiale (8, 2, 26-27), la Casa VIII, 2, 36, la Casa di Giuseppe II (8, 2, 38-39) (Kastenmeier, 2007: 138-143), la Casa di Cecilio Febo (8, 2, 36-37), la Casa delle Colombe a Mosaico (8, 2, 32-34), la Casa di Cesio Blando (7, 1, 40), la Casa del Marinaio (7, 15, 1-2), así como la Villa dei Quintili en la Via Appia (Basso, 2003: 529-546; George, 1997a: 19). En Hispania encontramos paralelos en la Casa n. ${ }^{\circ} 2$ de Munigua (Sevilla), cuya topografía propicia la construcción en dos niveles y su separación funcional (Gómez, 2006: 355).

\subsubsection{Domus 5F (Ilici)}

Otro eje de servicio se encuentra en esta domus de Ilici, datada entre los siglos I-v dC. Esta área se ubica al O de la vivienda y se comunica directamente con el peristilo redistribuidor (fig. 7). Desde la estancia 14, que cuenta con un horno panadero, se accedía a la galería sanitaria de desagüe que recorre toda la casa, presumiblemente para llevar a cabo tareas de mantenimiento.

Las estancias 16 y 17 han sido definidas por los excavadores como el lugar del baño y letrina de la vivienda. Por su pared S discurría una tubería de plomo, con sección oval de 7 x 5 cm, para el abastecimiento de agua (Sarabia y Cañavate, 2009: 106; Ramos, 1991: 76-77); sin embargo, la ausencia de un canal de desagüe en la supuesta letrina, la falta de sistemas de calefacción, y la suntuosa decoración a base de mármoles y opus tessellatum desaconsejan identificar estos espacios como letrinas y balnea.

La buena conservación de esta vivienda, con la planta prácticamente completa, nos permite estudiar la interrelación establecida entre el eje de servicio y el triclinium (9), ubicado al $\mathrm{N}$ del peristilo. Ambos espacios se encuentran próximos, lo que facilitaría el traslado de la comida, la retirada y cambio de platos, así como la comunicación de información y órdenes entre el triclinium y la cocina. El eje de servicio sería altamente accesible, ya que solo es necesario atravesar el peristilo, espacio dinámico y nódulo de la vivienda, para llegar de la cocina a la sala de banquetes. Respecto a la percepción de estos ambientes, su posición en un lateral del peristilo, fuera del eje axial del triclinium, impediría la posible conexión visual entre ambos. Es posible que solo desde la esquina SE de esta gran sala se pudieran vislumbrar las puertas de las áreas de servicio. Y, en cuanto a la percepción de olores y ruidos, a pesar de la proximidad ya comentada, el espacio descubierto entre ambos podría disminuir esos efectos (Foss, 1994: 38-42). 
Figura 7. Domus 5F (Ilici) (a partir de Ramos, 1991: 75; fig. 5).

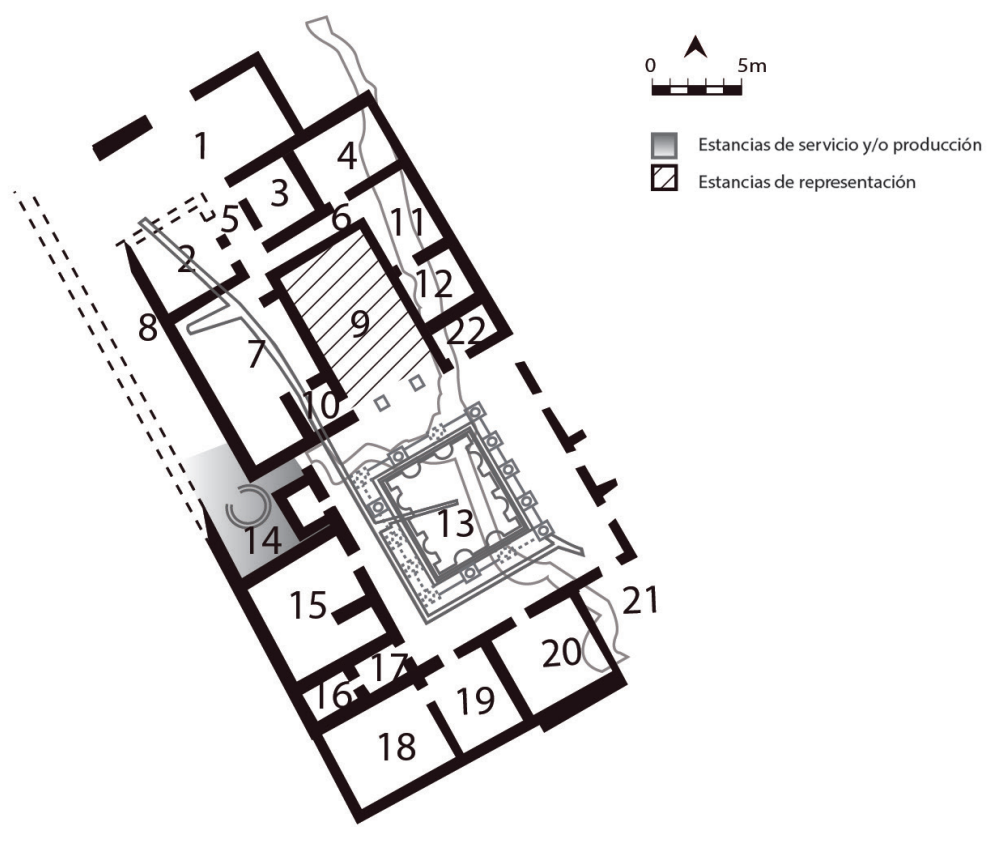

\subsection{Ambientes de servicio identificados por elementos estructurales fijos}

En el estudio de Salza sobre cocinas en el área campana, vemos cómo las casas más pobres poseían plataformas de ladrillos en forma de C o E para cocinar (Salza, 1978-1980: 240243). Estas estructuras de cocción, conocidas en las fuentes latinas como focus, foculus o foculare (Foss, 1994: 62-63), aparecen en los espacios domésticos de Lesera, Edeta y Valentia (fig. 4). Otra solución son aquellos hogares revestidos de tegulae y fragmentos de grandes vasos (Bonini, 2006: 99).

Debemos tener en cuenta que la difusión del banco de cocina, tan característico de la zona campana, no se produce de manera universal. El amplio uso de estos hogares se debe a la facilidad de su construcción y a la versatilidad de uso, adaptados a cocinar sobre brasas o llamas; por eso es la forma más difundida en todo el Imperio. Hay variaciones regionales: en Britannia son agujeros en el suelo, en Grecia son rectangulares y se ubican sobre el pavimento, en África prevalecen los braseros móviles. Normalmente se ubican en esquinas o con un apoyo en la pared, para facilitar el control de las llamas (Bonini, 2015: 464-466).

En territorio valenciano, se ha conservado este tipo de estructuras en dos espacios domésticos de Lesera. En la Domus 1, siglos I-II dC, el espacio distribuidor, tipo corredor, da acceso a la sala de representación y a un conjunto de espacios privados y de servicio, 


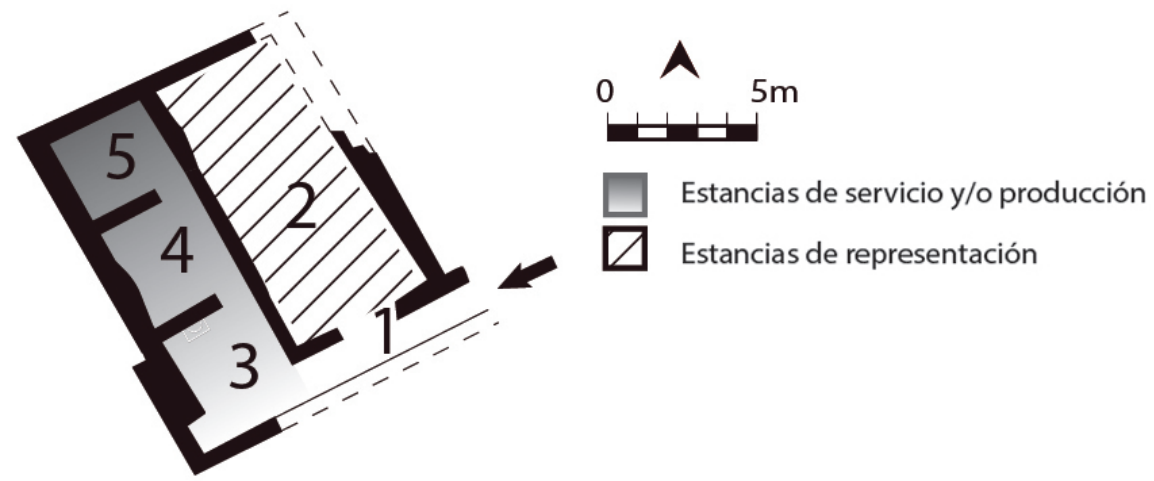

Figura 8. Domus 1 (Lesera) (a partir de Arasa, 2009: 68; fig. 52).

donde podríamos incluir la cocina y el resto de estancias a las que se accedía a través de ella (fig. 8).

La estancia identificada como cocina-despensa (3), cuyos muros presentan restos de encalado, cuenta con un hogar adosado al muro $\mathrm{N}$ de la estancia. Es una estructura de combustión rectangular $(78 \times 44 \mathrm{~cm})$, hecha con una hilada de ladrillos cocidos también rectangulares. Su interior está construido con tierra endurecida. Los ladrillos de los ángulos externos tienen unas dimensiones de $31 \times 15 \mathrm{~cm}$ (Arasa, 2009: 68-73) (fig. 4.a).

Encontraríamos paralelos de este hogar en la taberna 10 de la Domus I de Bilbilis (Calatayud, Zaragoza), con una estructura de mampuestos en forma de "high backed chair» o en la Casa de los Morillos de Iuliobriga (Retortillo, Cantabria), donde aparecieron dos fogones de ladrillo, uno de ellos apoyado en un tabique (Uribe, 2008: 602-603). Estos hogares, correspondientes al tipo I definido por Foss para las domus pompeyanas, son estructuras planas de mampostería, coronadas con una capa de baldosas, de morfología variada. El fuego se emplazaría sobre la superficie, y los recipientes se colocarían directamente sobre las brasas o sobre trípodes (Foss, 1994: 78-80). Su uso en algunas casas de la Grecia clásica, donde los fuegos se situaban contra las paredes o en las esquinas, es indicativo de una funcionalidad de cocina según Parisinou (2007: 220). Podemos ver este tipo de fuegos en la Casa de la cisterna abovedada en Morgantina (Tsakirgis, 2007: 227-228). En función de las dimensiones definidas por Kastenmeier para las cocinas, 10-15 m² (2007: 58-60), la cocina de Lesera presenta una medida ligeramente superior, con 16,8 $\mathrm{m}^{2}$. Desde el punto de vista de la proximidad con la estancia de convivium, se encuentra a escasos metros de ella y es altamente accesible. En este caso, el carácter cerrado de una casa de corredor, aunque tuviera ventanas, haría que las actividades culinarias fueran perceptibles desde el punto de vista del olfato y del oído. Además, el acceso a la vivienda, directamente en eje axial con este espacio, implicaría que los invitados pudieran observar, aunque fuera parcialmente, su interior. Todas estas características tienen una implicación social; no nos encontramos frente a una casa propia de la élite, donde el cuidado por la separación de 
Figura 9. Domus Sondeo 8 (Lesera) (a partir de Pérez et al., 2015: 271; fig.2).
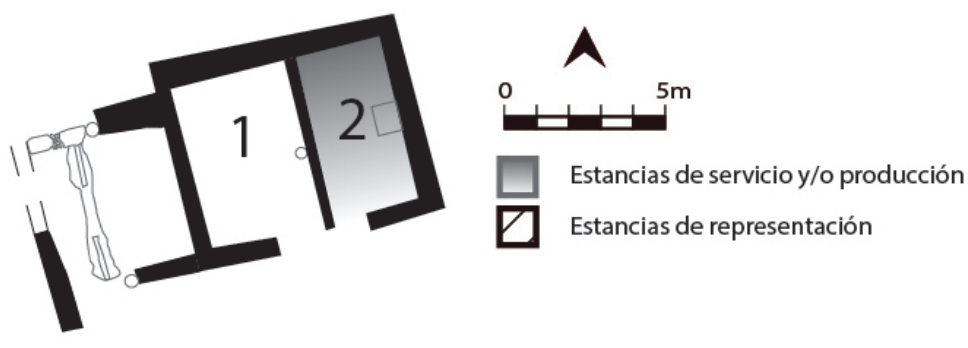

espacios sería más factible. La cocina se encuentra delimitada, al S y al O, por dos muros perimetrales, lo que facilitaría la construcción de una serie de vanos que proporcionarían iluminación y ventilación a un espacio donde se generarían humos y olores.

El ambiente 2 del sondeo 8 (Lesera) presenta dos momentos constructivos, que se dan entre los siglos II y III dC (fig. 9). En la segunda fase, se construye un hogar de cerámica, ligeramente más grande que el de la Domus 1, de $80 \times 62 \mathrm{~cm}$ (Pérez et al., 2015: 270-273). Su ubicación junto al muro E es idónea para facilitar el control de las llamas (fig. 4.b); además, el momento de construcción de esta estructura se acompaña de un hecho significativo que puede estar indicando el cambio de funcionalidad del espacio, como es la amortización de los estucados de las paredes de la fase anterior.

La Domus II (Edeta) contaba con un hogar sobre lateres quemados (fig. 4.c) (Vidal, 2018: 20-21), análogo a los encontrados en Lesera.

Entre los elementos estructurales fijos, los hornos son uno de los principales indicadores de una estancia de servicio. En territorio valenciano contamos con diversos hornos, dentro de los grandes ejes de servicio, como el de la cocina de la Domus del solar del Romeu (Saguntum), el horno panadero de la Domus 5F (Ilici), el de vidrio de la calle Sabaters-plaza de Cisneros (Valentia), el horno de metal de la fase republicana de la Domus de Terpsícore (Valentia) o el de función indeterminada de la calle Roc Chabàs (Valentia).

\subsection{Ambientes de servicio identificados por su cultura material mueble}

No en todos los casos tenemos elementos estructurales que nos permitan identificar estancias donde se llevarían a cabo actividades que requieran de un focus y, por tanto, impliquen la transformación de alimentos. En otras ocasiones hemos de guiarnos por el material cerámico, tal como indica Allison, superando la tradicional identificación a través de elementos arquitectónicos, decorativos o planimétricos (2004: 1-11).

En el caso de la Domus dels Peixos (Saguntum), siglos II-III dC, la cultura material mueble es el elemento determinante para su identificación (fig. 10). La estancia (4) (3,44 × 3,70 m) se encontraba al $\mathrm{N}$ del patio porticado y al E de una taberna. 


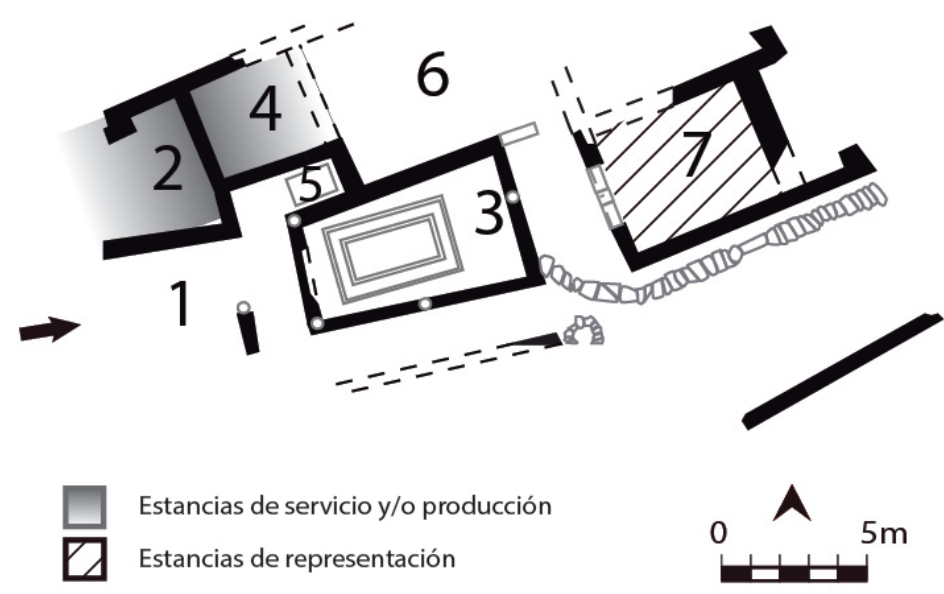

Figura 10. Domus dels Peixos (Saguntum) (a partir de Antoni, 2011: 96; fig. 6).

Aunque los investigadores la identificaron como una posible culina, no se han localizado indicios estructurales (hogar, horno...) que lo confirmen. Aunque el hallazgo de fragmentos de pintura mural puede resultar contradictorio con una estancia de servicio, su presencia pudiera estar indicando una conversión del espacio noble en estancia de servicio, pues, además de polifuncionales, los espacios son susceptibles de mutar su funcionalidad a lo largo del tiempo (Basso, 2003: 523; Kastenmeier, 2007: 22). El hecho de que las pinturas murales se conserven sin ennegrecer no descartaría una funcionalidad de servicio, ya que Salza ha observado que los lararios pintados de las cocinas pompeyanas no aparecen oscurecidos por el humo, por lo que podrían usar brasas traídas de fuegos realizados en los patios. Por consiguiente, es posible que la ausencia de bancos de cocina, casi exclusivamente campanos, se deba al uso de braseros móviles de terracota o metal, que una vez inservibles se fundirían, de ahí su ausencia (Salza, 1978-1980: 251-282; Allison, 2004: 102-103). El uso de los braseros frente a los hogares como estructuras fijas aumenta la flexibilidad; se podría cocinar en el patio o en el pórtico, y esto haría innecesarias las chimeneas permanentes, pues el carbón una vez encendido casi no humea (Tsakirgis, 2007: 229-231).

Por tanto, es su material cerámico destinado a la preparación, el consumo y el almacenaje de alimentos lo que nos ayuda a identificarlo como un espacio de servicio. Destaca la cerámica africana de cocina, cazuelas formas Ostia III y Lamb 10A-Hayes 23B, cazuelas de fondo estriado y borde ahumado. La cazuela Ostia III se comienza a producir a finales del siglo II dC, consolidándose en el segundo tercio del siglo III dC, así como la Lamboglia 10A, que perdura desde la segunda mitad del siglo in hasta el IV dC. También aparecieron sobre el pavimento numerosos fragmentos de dolia, uno de ellos con un diámetro de base de 33 cm (Antoni et al., 2002: 108-109; Antoni, 2010: 77-85). 
La cronología avanzada de los materiales podría explicar una funcionalidad residencial o noble en una primera fase, relacionada con su ornamentación y acceso directo al patio, y su posterior cambio de funcionalidad en un segundo momento (siglos II-III dC), cuando se sella su conexión con el espacio distribuidor y se almacenan los materiales anteriormente referidos, pasando a formar parte del área de servicio de la domus, del mismo modo que sucedió en la Casa del Criptopórtico (I, 6, 2-4) (Pompeya), donde una estancia ubicada en un corredor subterráneo tenía una función de representación hasta que, tras el terremoto del 62 aC, pasó a usarse como almacén, conservando sus ricas pinturas originales (Basso, 2003: 525). La Casa dei Cei (I, 6, 15) (Pompeya) cuenta con dos habitaciones decoradas con pinturas murales; en una de ellas se colocaron estanterías sobre la pared pintada y en la otra se encontraron indicios de un hogar, testimonio del cambio de funcionalidad (Nevett, 2010: 112).

Además, la estancia de la Domus dels Peixos se encuentra ubicada junto al muro perimetral N, lo que facilitaría la salida de humos a la calle. Por otra parte, es reseñable su relación planimétrica con una de las estancias más enigmáticas de la domus (5), pavimentada con suelo hidráulico, con molduras de media caña y de reducidas dimensiones, que podría desempeñar funciones de almacenaje de agua, por lo que cumpliría con una de las instalaciones básicas asociadas a las cocinas (Foss, 1994: 42-43). En la Casa dei Postumii (VIII, 4, 4) (Pompeya), dentro de la cocina, se encontró un banco de trabajo de mármol apoyado en el borde de una balsa. Si el ambiente 5 fuera una balsa asociada a la estancia (4), estaríamos frente a un espacio que requeriría una gran cantidad de agua, con posible destinación comercial o semicomercial (Kastenmeier, 2007: 30-31); además, no debemos olvidar que, aunque sin conexión aparente, este espacio 4 es contiguo a la estancia 2, identificada como taberna.

Por otra parte, su único acceso a través de la posible estancia de representación (6), abierta al patio principal y decorada con pinturas murales, pudiera estar reflejando una asociación entre estancia de servicio y posible sala de banquetes, aunque el estado de conservación nos impide aseverarlo. La única estancia que parece confirmar esta funcionalidad es la habitación 7, por su decoración, ubicación en planta y morfología. A partir de aquí, podemos decir que ambos espacios se encuentran relativamente próximos desde el punto de vista físico, lo que facilitaría el tránsito de esclavos y platos. Sin embargo, su accesibilidad es más cuestionable: para alcanzar el triclinium desde la cocina se debía atravesar el patio porticado (3) y la estancia (6); la percepción de las actividades de servicio quedaría totalmente anulada respecto al triclinium (7), algo totalmente contrario a lo que sucedería en la estancia 6, que al encontrarse aneja a la cocina/almacén, quedaría demasiado expuesta a estas actividades, lo que nos hace replantearnos su funcionalidad.

\section{4. Áreas de producción}

En este apartado agrupamos aquellos ambientes en los que se han detectado estructuras fijas funcionales propias de espacios de producción, como almazaras, molinos, hornos de 
vidrio, de metal o de pan. En este sentido, nos gustaría resaltar la dificultad de identificar y justificar la presencia de estos espacios en ambientes domésticos privados de carácter urbano, cuando normalmente es algo que esperamos encontrar o bien en espacios domésticos rurales, o bien en talleres específicos sin funcionalidades domésticas.

Dentro de las áreas productivas, reciben especial atención las relacionadas con la actividad agrícola, en particular las instalaciones vinícolas y olearias, que constituían las producciones más beneficiosas en la antigüedad. En nuestro caso lo complicado es deducir si nos encontramos ante espacios dedicados al autoabastecimiento o si se destinaban al comercio (Uribe, 2008: 607-608). Estas instalaciones productivas son espacios aislados de las zonas residenciales, y pudieran reproducir a pequeña escala las actividades desarrolladas en ámbitos rurales; si bien la calidad sería la misma, puede que la destinación de los productos sea diversa, no para el gran comercio transmarino, sino para satisfacer las necesidades internas (Bonini y Rinaldi, 2003: 200).

Hay que tener en cuenta que la construcción de espacios para la elaboración de vino o aceite solo se documenta cuando el volumen de producción es medio-alto, superando los límites del autoabastecimiento, por eso es difícil identificar estas actividades en el entorno urbano; además, como apunta Corrales (2014: 326), normalmente las viviendas que cuentan con esta clase de espacios destacan por su multifuncionalidad, donde se compaginan zonas residenciales con bloques de servicio y zonas de producción.

En la Domus 1 (Lesera), siglos I-II dC, se encontraron estancias donde se pudieron llevar a cabo actividades de producción textil (Arasa, 2009: 68-69). El hecho de que se trate de una casa modesta hace suponer que las actividades de descanso se podrían llevar a cabo en las estancias 4 y 5, donde además se realizarían actividades de producción (fig. 8). A pesar del insuficiente alzado de los muros, la presencia de elementos relativos a actividades textiles implica la necesidad de iluminación externa suficiente, por lo que se deduce que en el muro perimetral O se abriría una serie de vanos, que además contribuirían a la ventilación de la cocina, en eje con estas estancias.

En la estancia (4) de la Domus de la calle Roc Chabàs (Valentia), último tercio de los siglos I aC-I dC, aparecieron los restos de combustión de un horno del que no hay suficientes elementos para definir su funcionalidad. Esta habitación tendría el acceso por el flanco E. El horno estaba adosado a los muros N, E y O. Su cámara de combustión se componía de dos receptáculos comunicados entre sí por un arco de ladrillos de adobe que se adosaba al muro N. Este arco delimitaba al O con un espacio de unos $40 \mathrm{~cm}$ que pudiera ser una chimenea. La base del horno estaba formada por una gruesa capa de arcilla endurecida por su exposición al fuego; esta misma capa de arcilla se encontraba recubriendo la zona del arco y el interior del muro $\mathrm{N}$ de la estancia (fig. 11.a); el paramento tenía una forma cóncava en su parte inferior y ejercía de pared de la cámara de combustión. Los excavadores pensaron que podía tratarse de un horno cerámico (Soriano et al., 1995: s.p.); aunque faltan datos que lo corroboren, podría tener un paralelo en la Domus del antiguo Portal de Magdalena (Ilerda, Lleida), donde se ha encontrado toda una zona de servicio y productiva, con la presencia de un posible horno de cerámica (Cortés, 2009: 605); sin 
a.

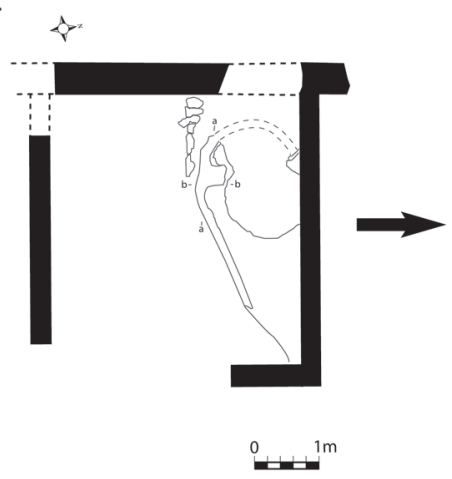

b.
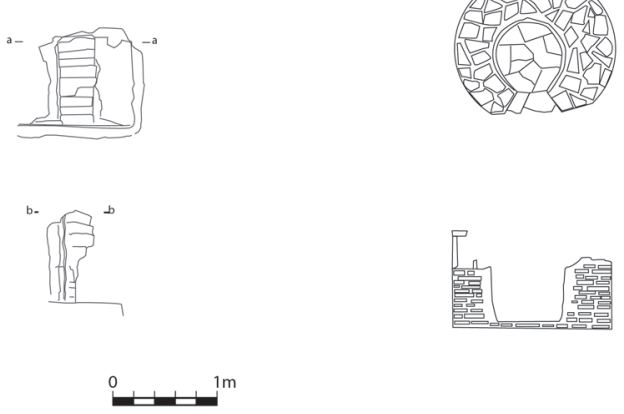

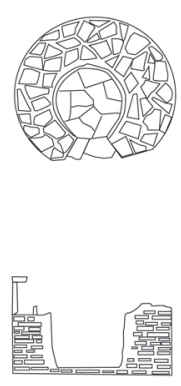

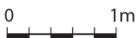

Figura 11. Estructuras fijas productivas: a. Horno de la estancia 4 de la Domus de la calle Roc Chabàs (Valentia) (a partir del Archivo SIAM); b. Horno de vidrio, Domus de la calle Sabaters-plaza Cisneros (Valentia) (a partir de Albiach y Soriano, 1991b: 82; fig. 6).

embargo, en un contexto doméstico este espacio pudiera responder más a un horno para cocción de pan o alimentos.

El ambiente 2 de la fase republicana de la Domus de Terpsícore (Valentia) era una gran superficie pavimentada, pero sin muros que la delimitaran; en ella ha aparecido una fosa con una considerable cantidad de nódulos de hierro, lo que pudiera indicar un área de fundición. En el interior de la estancia 4 apareció una estructura rectangular de adobe $(3 \times 0,80 \mathrm{~m})$ colmatada por cenizas y abundantes restos de escoria de hierro; esta estructura no constituye por sí misma un auténtico horno, pero sí aparece relacionada con alguna de las fases de la metalurgia del hierro, que pudiera ser de tipo familiar (Marín et al., 1991: 64; Marín y Matamoros, 1994: 52).

En la Domus de la calle Sabaters-plaza de Cisneros (Valentia), siglos II-IV dC, se ha conservado un eje de servicio con espacios para la producción (fig. 5). La supuesta domus fue el resultado de una remodelación de un edificio comercial, que se llevó a cabo hacia la segunda mitad del siglo III dC (Sánchez y Ramón, 2014: 227). En el extremo SE de la estancia 1 apareció un horno de planta circular, de $65 \mathrm{~cm}$ de diámetro y $90 \mathrm{~cm}$ de altura conservada (fig. 11.b), construido con ladrillos y tegulae trabados con barro. Los ladrillos aparecieron rubificados, mientras que las paredes conservaban goterones de pasta vítrea y su altura llegaba hasta un banco en el que se colocaban los crisoles. Al S del horno se hallaba un sillar de piedra caliza de $45 \times 45 \times 50 \mathrm{~cm}$; donde se apoyaría donde se apoyaría la caña para el soplado del vidrio. Toda la unidad estratigráfica que rellenaba el horno contenía restos de cenizas y fragmentos de ladrillos. Frascos, botellas, ungüentarios, cuencos, copas y adornos de vidrio aparecen esparcidos por toda el área excavada (Albiach y Soriano, 1991a: 59). Un segundo cuerpo de $40 \mathrm{~cm}$ de ancho, que se mantenía a la altura del banco corrido, fue interpretado como el lugar donde se colocarían los crisoles; se planteó la existencia de una segunda cámara, aunque no se encontraron restos de bóveda. La estructura interpretada como el apoyo para el soplado guarda similitudes con otra encontrada en la la calle Honda 
n. ${ }^{\circ} 17$ (Cartagena). Tipológicamente, estos hornos, que suelen tener plantas de tendencia circular salvo excepciones, son estructuras simples hechas de ladrillos y tejas, con restos de vitrificación y un diámetro interno entre los 50 y los $100 \mathrm{~cm}$ (Sánchez y Ramón, 2014: 229-230). Se han encontrado ladrillos entre los que se ha filtrado vidrio fundido, que parecen corresponderse con parte de la estructura del horno.

La remodelación de este espacio, en la segunda mitad del siglo III dC, coincide con el momento en el que Valentia sufrió diversos episodios violentos que provocaron su transformación; la reducción de los espacios urbanizados fue una de sus primeras consecuencias. En la zona $\mathrm{N}$ de la ciudad los edificios abandonados y en ruinas albergarían instalaciones artesanales, como fue el caso de este taller vidriero, instalado en un barrio artesanal cerca del puerto fluvial, que habría estado funcionando entre finales del siglo in y el siglo iv dC. El momento final del taller viene marcado por un vaso decorado con cabujones del siglo v dC, encontrado en los niveles de abandono (Sánchez y Ramón, 2014: 238-240).

En la habitación 4 ha aparecido un molde de bronce rectangular relacionado con la producción de vidrio. Quizá por su ubicación frente al horno, su funcionalidad estaría relacionada con la actividad manufacturera de vidrio (Albiach y Soriano, 1991a: 59).

La cuestión que queda por dilucidar es si este taller vidriero formaría parte de un espacio doméstico más amplio o si, por el contrario, no formaría parte de una vivienda. La presencia de una cocina, zona de almacenes... nos hace pensar en la posibilidad de que formara parte de un espacio doméstico, razón por la que lo incluimos en nuestro estudio, aunque no descartamos la hipótesis alternativa.

En la Domus 3F (Ilici), siglos I-V dC, apareció una serie de estancias (4 y 5) de morfología irregular, al S de un peristilo con estanque polilobulado (fig. 12). En su interior se encontró una almazara, con la prensa de aceite de piedra de mármol gris, y una gran muela circular de piedra y granos de cereales, lo que constituiría un área de molino (Ramos, 1975: 184-185; 1991b: 74; 1992: 156-159). Estas estancias, a pesar de encontrarse abiertas a un suntuoso peristilo, debían de hallarse alejadas de las salas de representación principales.

Encontramos paralelos de producción de vino y/o aceite en la zona catalana, en las casas de la calle Lladó, en la habitación 13 de la Domus dels Dofins, en la habitación 10 de la Domus de l'Heura y en la segunda fase de la casa de la calle Fluvià n. ${ }^{\circ} 23$, todas ellas en Baetulo (Badalona, Barcelona); en la casa de la calle Fortuny n. ${ }^{\circ} 12-14$, Tarraco (Tarragona) (Cortés, 2009: 518) y en la casa de la calle Bisbe Caçador, Barcino (Barcelona) (Cortés, 2009: 541). También en la casa n. ${ }^{\circ} 2$ de Munigua (Sevilla) se halla una prensa de aceite (Gómez, 2006: 355). Igualmente, se han encontrado espacios productivos relacionados con la agricultura dentro de residencias urbanas africanas, como la Casa dei Servizi y la Casa de Bacco e Arianna en Thuburbo Maius (Túnez) (Bonini y Rinaldi, 2003: 1999).

Respecto al molino de grano, las diversas publicaciones sobre esta domus no especifican si se trataría de un molino de mano o de un molino rotatorio bicónico. Hay que matizar que en Hispania las evidencias de este tipo de molinos son escasas; algunas metae han sido encontradas en Augusta Emerita (Mérida), piezas de mayores dimensiones en la villa romana del Cogoll (Vilallonga del Camp, Tarragona), otra meta en Aquae Flaviae (Chaves, Portugal) 
Figura 12. Domus 3F (Ilic) (a partir de Ramos, 1991: 74; fig. 3).
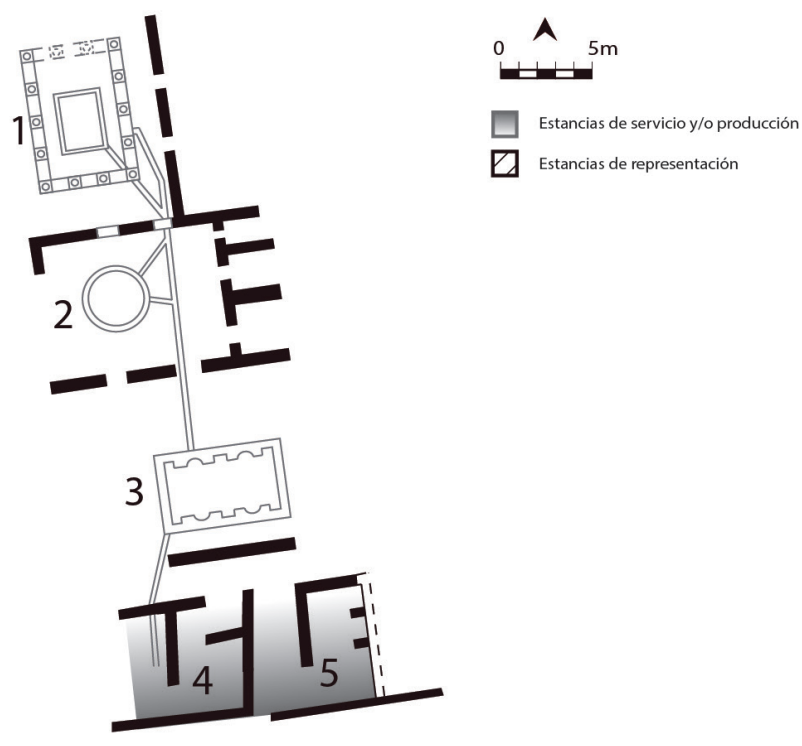

y dos piezas de molinos del tipo pompeyano en Asturica Augusta (Astorga) (Bustamante et al., 2014: 352).

La estancia 14 de la Domus 5F (Ilici) (fig. 7), siglos I-V dC, cuenta con un horno panadero, furnus (Foss, 1994: 62-63), construido en adobe con cubierta de cúpula. No debemos olvidar el alto valor nutritivo y energético del grano, que lo convirtió en un alimento indispensable en la alimentación diaria del ciudadano romano, con un aporte del 70-75\% de las calorías de la dieta clásica. En el proceso de panificación, la cocción se lleva a cabo tras el amasado y moldeado del producto; los hornos suelen ser de pequeñas dimensiones, cerrados por una cúpula y con una abertura lateral por la que se introduciría el pan mediante palas de madera (Bustamante et al., 2014: 333-344).

Aunque la presencia del horno de pan implique que pudiera tratarse de una estancia descubierta, pues los autores clásicos aconsejaban que en las villas los hornos para el pan se situaran en terreno abierto para reducir el peligro de incendio (Vitr., De Arch., 6.6. 1-2.5); (Col., Rust., 1.6.21; Dig., 9, 2, 27, 10), no debemos olvidar que hay varios testimonios pompeyanos que albergan pistrinae en estancias subterráneas, aunque constituyan una excepción: la Casa del Centenario (9, 8, 3-7); la Casa del Menandro (I, 10, 4); la Casa di Giuseppe II (8, 2, 39); la Casa del Marianaio (7, 15, 1-2); la Casa del Criptopórtico (1, 6, 2-4); la Casa VIII, 2, 14-16; la Casa di Championnet (8, 2 1), o la Casa di Gaio Nivillio (6, ins. occ., 13) (Busana, 2003: 497-509). En el caso de la Domus 5F (Ilici) consideramos que tanto el horno de pan, como todo el sector de servicio, se encuentran junto al muro perimetral O, pudiendo abrir ventanas o chimeneas a la calle (Kastenmeier, 2007: 58-60) o bien dejar al descubierto el espacio donde se encontró el horno. 
En algunas domus de ciudades hispanorromanas se han registrado furni de planta circular, cuya producción se destinaría al consumo familiar. Hasta el momento, los hornos de pan se han localizado en grandes domus, poseedoras de varias estancias de servicio, pudiendo vincularse a cocinas. Hornos circulares se encuentran en Augusta Emerita (Mérida), como la Casa del Anfiteatro; en la Domus de Salvius de Cartagena y en el vicus de Baños de la Reina (Alicante) (Bustamante et al., 2014: 350; Salido y Bustamante 2014: 43).

Un aspecto importante cuando encontramos este tipo de estructuras de producción, radica en definir si tendrían una destinación privada o pública; es posible que tuvieran una doble función, para cubrir las necesidades domésticas y para cumplir un servicio externo (Busana, 2003: 510). En Italica (Santiponce, Sevilla), en la esquina S de la Casa del Planetario, se localizó una pistrina con un acceso directo desde el exterior, mientras la Casa de los Pájaros presenta un horno de pan en una de las tabernae situadas junto a la entrada, aunque la instalación no tiene acceso directo desde la casa, por lo que tendría una función artesanal y de venta directa a la calle (Bustamante et al., 2014: 347; Gómez, 2006: 241).

No obstante, nos gustaría matizar que la existencia de pistrinae con venta directa hizo que estos hornos no fueran necesarios en las casas, en las que los encontraríamos más sencillos, donde el pan se preparaba bajo las brasas del hogar como pudiera ser el de la Domus tardía del solar del Romeu (Saguntum). Además, los propietarios de tabernae, cauponae y pistrinae tendrían acceso a estos hornos de sus negocios (Salido y Bustamante, 2014: 43).

\section{Conclusiones}

La tarea de identificar estas estancias de servicio, producción y comercio ha resultado ardua, ya que en la mayoría de los casos no encontramos indicios estructurales que nos permitan identificarlas con claridad.

Entre las muestras recogidas, podemos establecer jerarquizaciones sociales en función del espacio dedicado a estos ambientes en cada vivienda (fig. 13). Distinguimos grandes casas con amplios ejes de servicio, como el encontrado en la domus bajoimperial del solar del Romeu (Saguntum) (fig. 13.d), signo de la disponibilidad espacial y económica. Este espacio concuerda con la ampliación del espacio urbanizable de la ciudad de Saguntum en época bajoimperial, hasta el límite con el río Palancia. Constituye otro eje el aparecido en la Domus II de Edeta (fig. 13.e), con una estancia central que conservaba un hogar, flanqueada por dos estrechas estancias que pudieron constituir almacenes; prueba de la riqueza de esta domus son las pinturas murales y el hipocaustum que aparecieron en la parte noble. El eje de servicio de la Domus de la calle Sabaters-plaza de Cisneros (Valentia) (fig. 13.f) cuenta, además, con un horno de vidrio, por lo que entraña actividades productivas. La Domus del Peristilo de Lucentum (fig. 13.g), de confirmarse la funcionalidad de 

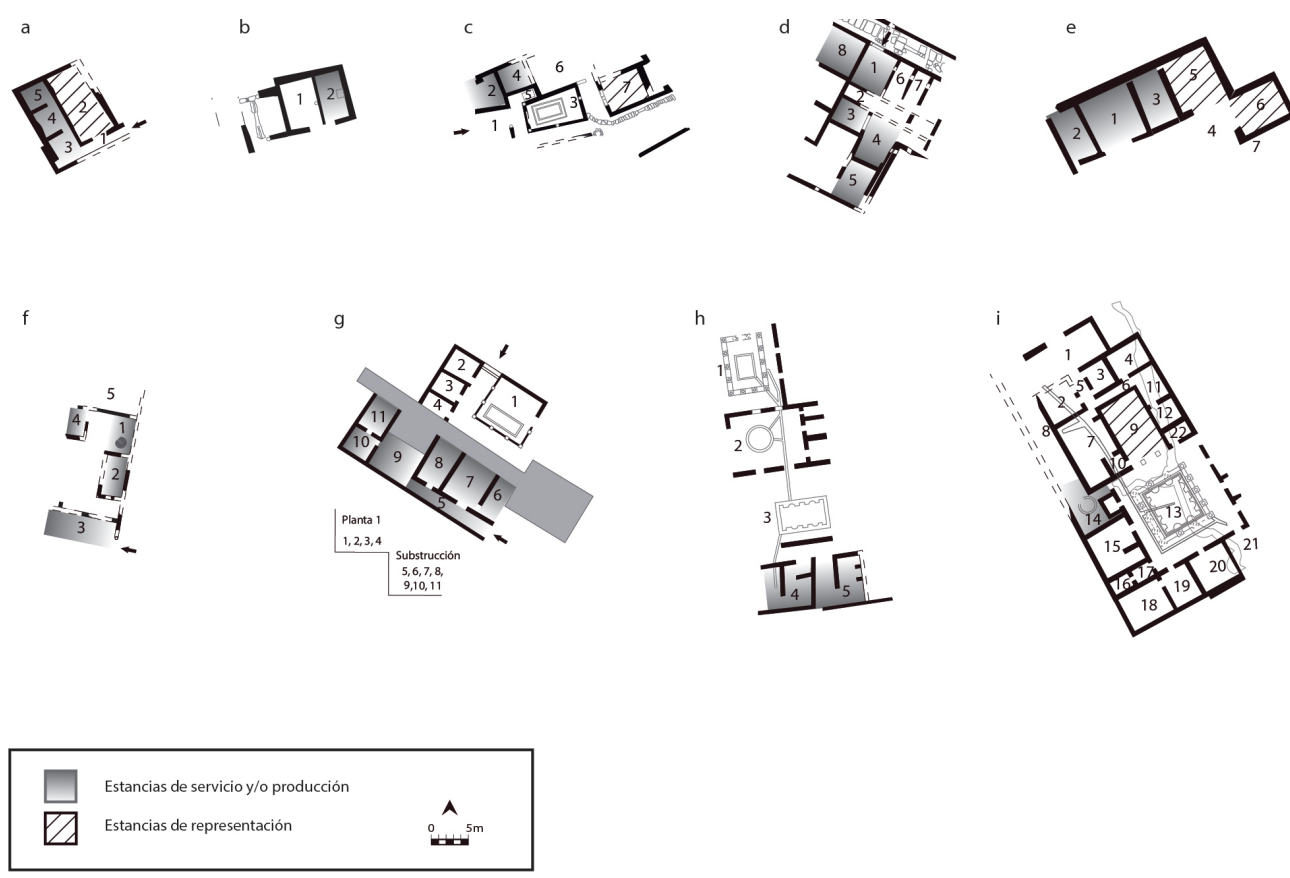

Figura 13. Domus valencianas con presencia de ambientes de servicio: a. Domus 1 (Lesera); b. Domus Sondeo 8 (Lesera); c. Domus dels Peixos (Saguntum); d. Domus tardía del solar del Romeu (Saguntum); e. Domus II (Edeta); f. Domus de la calle Sabaters-plaza Cisneros (Valentia); g. Domus del Peristilo (Lucentum); h. Domus 3F (llici); i. Domus 5F (llici).

servicio de las estancias extramuros, sería un ejemplo único en el territorio valenciano de adaptabilidad al espacio edificable mediante el sistema de las substrucciones. El sector de servicio identificado en la Domus 5F de Ilici (fig. 13.i) cuenta con un horno, probablemente de pan, una cocina y un acceso de mantenimiento a una galería subterránea de evacuación de aguas. La conclusión es que este grupo de viviendas, que contaron con espacios de servicio identificados mediante elementos fijos estructurales, como hogares y hornos, por ubicación, por materiales constructivos de fácil limpieza y mantenimiento o por la ausencia de decoración, forman parte de las viviendas más grandes del registro, con espacio suficiente para invertir esos metros cuadrados en ejes de servicio.

Por otra parte, solo en algunos casos, hemos podido identificar estancias de servicio mediante sus elementos estructurales. De las 13 domus analizadas por preservar ambientes de servicio, 6 domus presentan estructuras fijas como hogares, dos en Lesera, una en Edeta y una en Valentia, y dos hornos para cocinar aparecidos en la Domus tardía del solar del Romeu (Saguntum) y la Domus 5F (Ilici). Es evidente que la ausencia de bancos de cocina no significa que no existieran espacios para la preparación de alimentos, sino que el tipo de cocción se realizó de otros modos que dejan escasas evidencias arquitectónicas (Uribe, 
2008: 604). Únicamente hemos identificado una estancia de servicio en función de su cultura material mueble en la Domus dels Peixos (Saguntum) (fig. 13.c).

Otro aspecto que nos ha resultado interesante analizar son los espacios de producción dentro de las domus. Con base en la cultura material mueble encontrada, las pesas de telar de las estancias 4 y 5 de la Domus 1 (Lesera) (fig. 13.a) estarían relacionadas con procesos de confección textil, como sucede en la Domus de la Fortuna (Carthago Nova, Murcia) (Bermejo, 2014: 68). Además, aunque llamativo, hay una mayor cantidad de espacios productivos identificados gracias a estructuras fijas funcionales que de cocina: el horno de metal de época republicana en la Domus de Terpsícore (Valentia); el horno de vidrio de la calle Sabaters-plaza Cisneros (Valentia); la almazara y el molino de grano de la Domus 3F (fig. 13.h) y el horno de pan de la Domus 5F (fig. 13.i), ambas en Ilici, lo que vendría a confirmar que los espacios domésticos urbanos no tendrían por qué aparecer desvinculados de ciertas actividades de producción.

Por último, nos gustaría hacer referencia a la interrelación establecida entre estos espacios de servicio, especialmente las cocinas, y las salas de banquetes, ya que ambas funcionarían como distintas piezas de uno de los mecanismos fundamentales en el modus vivendi de la élite romana, los actos de convivium. Dentro de la muestra recogida en territorio valenciano, únicamente tres ejemplares nos permiten estudiar esta relación, en función de los parámetros planteados por Foss (1994: 38-42), ya que los requisitos para el análisis es que se conserven en planta espacios de servicio y estancias de representación/banquete.

Tanto la Domus 5F (fig. 13.i) de Ilici como la Domus dels Peixos (Saguntum) (fig. 13.c) presentan sus cocinas próximas a los espacios de banquete; ahora bien, mientras la primera resultaría fácilmente accesible a través de un espacio dinámico como es el peristilo, la segunda debe atravesar el espacio distribuidor y una habitación cerrada y estática para llegar a la cocina, lo que reduciría la accesibilidad. Ambas gozarían de altos grados de aislamiento de olores y ruidos, y estarían fuera del eje visual de los invitados.

Un ejemplar interesante por sus implicaciones sociales es el de la Domus 1 de Lesera (fig. 13.a), prueba de cómo las clases modestas, que no disponen del espacio edificable suficiente ni de los medios económicos necesarios, se encontraron con la imposibilidad de separar físicamente los espacios de servicio de los de representación. Se encuentran próximos, accesibles, y las actividades llevadas a cabo por los siervos eran altamente perceptibles por los invitados, que, además, al acceder a la vivienda tendrían una conexión visual directa con la cocina.

La excepción es la Domus del Peristilo de Lucentum (fig. 13.g) que, aunque no conserva el triclinium, presuponemos que se encontraría a nivel de calle, mientras las estancias de servicio se ubicarían en una cota inferior. Esto vendría a demostrar cómo se apreciaba en la casa romana la marginación de estos espacios; aunque estarían difícilmente conectados con la parte noble de la casa, sería ventajoso su aislamiento de ruidos y olores, y su abastecimiento se realizaría a través de una entrada secundaria de servicio.

Por otra parte, estamos seguros de que numerosos ambientes domésticos de difícil atribución podrían desempeñar funciones de servicio, aunque no podamos corroborarlo debido a la ausencia de estructuras o restos materiales indicativos de dichas actividades. 


\section{Bibliografía}

ALBIACH, R. y SORIANO, R., 1991a, Actividades productivas y domésticas en una casa de Valentia, La casa urbana hispanorromana: ponencias y comunicaciones, Zaragoza, 57-60.

ALBIACH, R. y SORIANO, R., 1991b, Estudio de una "domus" romana de Valentia y de los niveles que la amortizaban, Saguntum 24, 75-96.

ALLISON, P., 2004, Pompeian Households: An Analysis of the material culture, Monographs 42, Los Ángeles.

ANTONI, C., 2010, La casa dels peixos. Una domus romana en la trama urbana de Sagunt (València), en L. ALAPONT y J. MARTÍ (eds.), III Jornades d'Arqueologia de València i Castelló, València, 77-85.

ANTONI, C., 2011, La casa dels peixos (Sagunt). Del vestigi arqueològic a l'exposició pública, Braçal: revista del Centre d'Estudis Camp de Morvedre 44, 87-105

ANTONI, C., HERNÁNDEZ, F. y DE ANTONIO, J. M., 2002, Noticia preliminar de les excavacions de la domus romana del solar del cinema Marvi (Sagunt), Arse 36, 99-116.

ARASA, F., 2009, La ciutat romana de Lesera, Ajuntament de Forcall, Vinaròs.

BASSO, P., 2003, I vani di deposito-stoccaggio, en P. BASSO y F. GHEDINI (eds.), Subterraneae Domus. Ambienti residenziali e di servizio nell'edilizia privata romana, Cierre Edizioni, Verona, 519-566.

BERMEJO, J., 2014, Household Archaeology, el análisis de las sociedades antiguas en la península Ibérica: definiciones, aplicaciones y posibilidades, Materialidades. Perspectivas en cultura material 2, 47-92.

BONINI, P., 2006, La casa nella Grecia Romana. Forme e funzioni dello spazio privato fra I e vi secolo, Quasar, Roma.

BONINI, P., 2015, Le cucine nell'Italia romana: domus e villae, en G. CUSCITO (coord.), L'alimentazione nell'antichità. Atti della XLVI settimana di studi aquileiesi, Editreg, Trieste, 455-474.
BONINI, P. y DAL PORTO, C., 2003, Le cucine, en P. BASSO y F. GHEDINI (eds.), Subterraneae Domus. Ambienti residenziali e di servizio nell'edilizia privata romana, Cierre Edizioni, Verona, 465-492.

BONINI, P. y RINALDI, F., 2003, Gli ambienti di servicio, en S. BULLO y F. GHEDINI (eds.), Amplissimae atque ornatissimae domus (Aug., civ., II, 20, 26); l'edilizia residenziale nelle città della Tunisia romana, Antenor Quadern, Padua, 189-220.

BUSANA, M. E., 2003, Gli ambienti di soggiorno nel sottosuolo delle domus e delle villae. Le domus. Roma, P. BASSO y F. GHEDINI (eds.), Subterraneae Domus. Ambienti residenziali e di servizio nell'edilizia privata romana, Cierre Edizioni, Verona, 220-228.

BUSTAMANTE, M., SALIDO, J., GIJÓN, E., 2014, La panificación en la Hispania Romana, en M. BUSTAMANTE y D. BERNAL (coords.), Artífices idóneos: Artesanos, talleres y manufacturas en Hispania, Consejo Superior de Investigaciones Científicas, Mérida, 333-369.

CHINER, P. y LÓPEZ, M., 1994, Noticia preliminar de las excavaciones de la Domus tardía del solar del Romeu (Sagunto), Saguntum 27, 229-237.

CORRALES, A., 2014, La arquitectura doméstica de Augusta Emerita, Universidad de Extremadura (tesis doctoral inédita).

CORRALES, A., 2016, La arquitectura doméstica de Augusta Emerita, Anejos de AEspA LXXVI, Madrid.

CORRALES, A., BERMEJO, J. y CAMPOS, J. M. 2016, La arquitectura doméstica urbana de las ciudades occidentales del Conventus Hispalensis: un ejercicio de crítica historiográfica, Lucentum 35 , 201-215.

CORTÉS, A., 2009, La arquitectura doméstica de las ciudades de Cataluña, Universidad Autónoma de Barcelona (tesis doctoral inédita). 
CORTÉS, A., 2014, L'arquitectura domèstica d'època tardorrepublicana $i$ altimperial a les ciutats romanes de Catalunya, Union Académique Internationale, Barcelona.

FOSS, P., 1994, Kitchens and dining rooms at Pompeii: the spatial and social relationship of cooking to eating in the roman household, University of Michigan (tesis doctoral inédita).

GEORGE, M., 1997a, Servus and domus: the slave in the Roman house, en R. LAURENCE y A. WALLACE-HADRILL (eds.), Domestic space in the roman world: Pompeii and beyond, JRA, Supplementary series 22, Portsmouth, 15-24.

GEORGE, M., 1997b, Repopulating the Roman House, en B. RAWSONY y P. WEACER (eds.), The Roman Family in Italy. Status, Sentiment, Space, OUP/ Humanities Research Centre of the Australian National University Series Oxford, 299-320.

GHEDINI, F., 2003, Per il riconoscimento degli ambienti della casa: notte di metodo, en P. BASSO y F. GHEDINI (eds.), Subterraneae Domus. Ambienti residenziali e di servizio nell'edilizia privata romana, Cierre Edizioni, Verona, 113-122.

GÓMEZ RODRÍGUEZ, A., 2006, La arquitectura doméstica urbana en época romana en la Bética, Universidad de Huelva (tesis doctoral inédita).

JANSEN, G., 1997, Private toilets at Pompeii: Appearance and operation, en S. E. BON y R. JONES (eds.), Sequence and Space in Pompeii, Oxbow Books, Oxford, 121-134.

JOYCE, H., 1979, Form, Function and Technique in the Pavements of Delos and Pompeii, AJA 83

(3), 253-263

KASTENMEIER, P., 2007, I luoghi del lavoro domestico nella casa pompeiana, "L'Erma» di Bretschneider, Roma.

LLORENS, M. y RIPOLLÉS, P. P., 1995, El depósito monetal de la domus A de Romeu: nuevas aportaciones a la circulación de moneda de bronce en Saguntum durante el siglo III d. C., Saguntum 28, 217-228.

MARÍN, C. y MATAMOROS, C. (1994):

Época romana. Desde sus orígenes en la época republicana a la antigüedad tardía, Hallazgos arqueológicos en el Palau de les Corts (I. LÓPEZ, C. MARÍN, R. MARTÍNEZ Y C. MATAMOROS, coords.), València, 39-178.

MARÍN, C., MATAMOROS, C. Y RIBERA, A. (1991): Restos de una vivienda de época republicana (s. II-I a. JC.) en Valentia: los hallazgos del Palau de les Corts Valencianes, La casa urbana Hispanorromana: ponencias y comunicaciones, Zaragoza, 61-66.

MONRAVAL, M., 1992, La pintura mural romana en el País Valenciano. Estado de la investigación y nuevos hallazgos. Metodología de excavaciónrecuperación, en J. L. JIMÉNEZ (ed.), I Coloquio de pintura mural romana en España, Ministerio de Cultura. Instituto de Conservación y Restauración de Bienes Culturales, València, 43-60.

NEVETT, L., 2010, Domestic space in Classical Antiquity, Cambridge University Press Cambridge.

OLCINA, M., 2009, Lucentum: Tossal de Manises. Alicante: arqueología e historia, Museo Arqueológico de Alicante MARQ, Alicante.

PARISINOU, E., 2007, Lighting dark rooms: some thoughts about the use of space in early Greek domestic architecture, en R. WESTGATE, N. FISHER y J. WHITLEY (eds.), Building communities. House, Settlement and Society in the Aegean and Beyond, BSAS 15, Exeter, 213-223.

PEÑALVER, T., 2018, Nueva propuesta interpretativa de la Domus del Peristilo de Lucentum (Tossal de Manises, Alicante), Spal. Revista de Prehistoria y Arqueología de la Universidad de Sevilla, 27.2, 225-240.

PÉREZ, R., DUARTE, F. X. y ARASA, F., 2015, Novena campanya d'excavacions a la ciutat romana de Lesera (La Moleta dels Frares, ForcallEls Ports), Saguntum 47, 269-273.

RAMOS, R., 1975, La ciudad romana de Illici: estudio arqueológico, Instituto de Estudios Alicantinos, Alicante.

RAMOS, R., 1991, La casa urbana hispanorromana en Illici, en La casa urbana hispanorromana. Ponencias y comunicaciones, Institución Fernando el Católico, Zaragoza, 69-78. 
RAMOS, R., 1992, La pintura mural romana en Illici, en J. L. JIMÉNEZ (ed.), I Coloquio de pintura mural romana en España, Ministerio de Cultura. Instituto de Conservación y Restauración de Bienes Culturales, València, 155-160.

RIVA, S., 1999, Le cucine delle case di Ostia, Mededeelingen van het Nederlandsch Historisch Instituut te Rome/MNIR 58, 117-128.

SALIDO, J. y BUSTAMANTE, M., 2014, Pistrina Hispaniae: panaderías, molinerías y el artesanado alimentario en la Hispania romana, Éditions Monique Mergoil, Montagnac.

SALZA, E., 1978-1980, Cucine e quartieri servili in epoca romana, Rendiconti della Pontificia Accademia romana di archeologia, 51-52, 237-294.

SÁNCHEZ, M. D. y RAMÓN, A., 2014, La producción de vidrio en Valentia. El taller de la calle Sabaters, Lucentum 33, 215-242.

SARABIA, J. y CAÑAVATE, V., 2009, La arquitectura doméstica romana en la Alcudia de Elche. La Domus 5-F, Lucentum 28, 89-110.

SERRANO, M. L., 2000, Hallazgos arqueológicos de la Plaza de Cisneros n. ${ }^{\circ} 6$ de Valencia, en J. PASCUAL y R. SORIANO (coords.), L'arqueologia fa Ciutat: les excavacions de la Plaça de Cisneros, Ajuntament de València, València, 9-22.
SORIANO, R., RUIZ, E. y LÓPEZ, I., 1995, Informe de la IV Campaña de Excavaciones arqueológicas en el $n{ }^{\circ} 2$ de la calle Historiador Chabás (Valencia). Eneromayo 1994, Archivo SIAM (memoria inédita).

TSAKIRGIS, B., 2007, Fire and smoke: hearths, braziers and chimneys in the Greek house, en R. WESTGATE, N. FISHER y J. WHITLEY (eds.), Building communities. House, Settlement and Society in the Aegean and Beyond, BSAS 15, Exeter, 225-231.

URIBE, P., 2008, La edilicia doméstica urbana romana en el cuadrante Nordeste de la Península Ibérica (ss. I a.C. - III d.C.), Universidad de Zaragoza (tesis doctoral inédita).

URIBE, P., 2015, La arquitectura doméstica urbana romana en el valle medio del Ebro (siglos II a.C.- III p.C.), Aquitania, sup. 35, Burdeos.

VIDAL, X., 2018, Edeta. Urbanisme en una ciutat romana ss. I-III d.C., Lauro. Quaderns d'història $i$ societat 11, 10-27.

WALLACE-HADRILL, A., 1988, The social structure of the Roman House, PBSR 56, 43-97.

ZACCARIA, M., 2003, Substructiones, en P. BASSO y F. GHEDINI (eds.), Subterraneae Domus. Ambienti residenziali e di servizio nell'edilizia privata romana, Cierre Edizioni, Verona, 65-112.

ZANKER, P., 1993, Pompei. Società, immagini urbane e forme dell'abitare, Einaudi, Turín. 
